\title{
Synergistic Emission Reduction of Particulate Pollutants in Coal-fired Power Plants Using Ultra-low Emission Technology
}

\author{
Leixing Tao ${ }^{1}$, Yanyan Wang ${ }^{1}$, Chunmei Yue ${ }^{1}$, Zhigang Shen ${ }^{2}$, Zhichao Liu ${ }^{2}$, Qizhen Liu ${ }^{3}$, \\ Junchao Lu', Jian Wang ${ }^{1}$, Honglei Ding ${ }^{*}$, Weiguo Pan ${ }^{*}$
}

${ }^{1}$ Shanghai Minghua Power Science \& Technology Co., Ltd., Shanghai 200090, China

${ }^{2}$ Shanghai Chuanglan Testing Technology Co., Ltd., Shanghai 200233, China

${ }^{3}$ Shanghai Environmental Monitoring Centre, Shanghai 200235, China

${ }^{4}$ Shanghai University of Electric Power, Shanghai 200090, China

\begin{abstract}
The total particulate matter (TPM) is a crucial indicator when evaluating flue gas emissions from coal-fired units. TPM contains solid and liquid contaminants and condensable particulate matter (CPM), which is mainly composed of sulfate and various anions, cations, and metal ions. This study selected three typical large-capacity coal-fired power plants in Shanghai retrofitted with ultra-low emission technology and monitored their emissions of $\mathrm{PM}_{2.5}, \mathrm{SO}_{3}$, and CPM during power generation. The results showed that the plants achieved comprehensive removal rates of 99.689-99.878\% and 86.99-92.92\% for $\mathrm{PM}_{2.5}$ and $\mathrm{SO}_{3}$, resulting in emitted concentrations of approximately 0.99-1.79 and 1.91-2.50 mg m ${ }^{-3}$, respectively, which are considerably lower than those associated with the traditional flue gas process. Additionally, a significant decrease in the emitted filterable particulate matter (FPM) caused a simultaneous decrease in CPM. After being equipped with the ultra-low emission technology, the units displayed a 76\% reduction in the emitted FPM concentration and a smaller FPM/CPM ratio (1:2 vs. 1:1). The emitted TPM (the sum of CPM and FPM) was reduced by $82 \%$, with an average measured concentration of $7.36 \pm 3.56 \mathrm{mg} \mathrm{m}^{-3}$. The values we obtained are representative and provide basic data for environmental assessment and local environmental policy formulation.
\end{abstract}

Keywords: Ultra-low emission; Total particulate matter; Condensable particulate matter; $\mathrm{PM}_{2.5} ; \mathrm{SO}_{3}$.

\section{INTRODUCTION}

China is a large energy-consuming country. In 2017, China's total energy consumption was 4.49 billion tons of standard coal. Coal consumption accounted for $60.4 \%$ of the total primary energy (Han et al., 2018). Coal-fired power generation is crucial in China's power industry and is expected to remain the primary source of power in the foreseeable future.

Coal combustion, being one of the main sources of air pollution in China, considerably affects the environment (Chen et al., 2019). According to the requirements of the standard GB13223-2011, "Air Pollutant Emission Standards for Thermal Power Plants," the emission concentrations of particulate matter $(\mathrm{PM})$, sulfur dioxide $\left(\mathrm{SO}_{2}\right)$, and $\mathrm{NO}_{x}$ must be lower than the standard limits of 20,50 , and $100 \mathrm{mg} \mathrm{m}^{-3}$, respectively. Therefore, all power plants in China had been

\footnotetext{
* Corresponding authors.

E-mail address: hlding2005@163.com (H. Ding); panweiguo@shiep.edu.cn (W. Pan)
}

equipped with flue gas denitrification (FGD), dust removal, and desulfurization systems by 2013. In the next 5-6 years, the development of ultra-low emission coal-fired units have gone through technical research, the demonstration of vital equipment (wet electrostatic precipitator [ESP], single-tower high-efficiency desulfurization and dust-removal integrated technology, among others), engineering demonstration, and large-scale promotion and application at the national level, especially in the central and eastern regions. Ultra-low emissions values of $\mathrm{PM}, \mathrm{SO}_{2}$, and $\mathrm{NO}_{x}\left(5,35\right.$, and $50 \mathrm{mg} \mathrm{m}^{-3}$, respectively) have been realized from flue gas. Despite an increase in the unit capacity, a considerable reduction has been achieved in the pollutant emission levels in coal-fired power generation. The usage of ultra-low-pollutant-emission technology has been extended to steel, cement, and other industries. Chinese ultra-low-pollutant-emission technologies have become the leading environmental protection technology in the world.

The ultra-low emission retrofit for coal-fired units has reduced the effect of $\mathrm{PM}, \mathrm{SO}_{2}, \mathrm{NO}_{x}$ on the environment (Zhao et al., 2015). The synergistic control effect of this technology promotes the considerable reduction of sulfur trioxide $\left(\mathrm{SO}_{3}\right)$, fine particulate matter $\left(\mathrm{PM}_{2.5}\right)$, condensable 


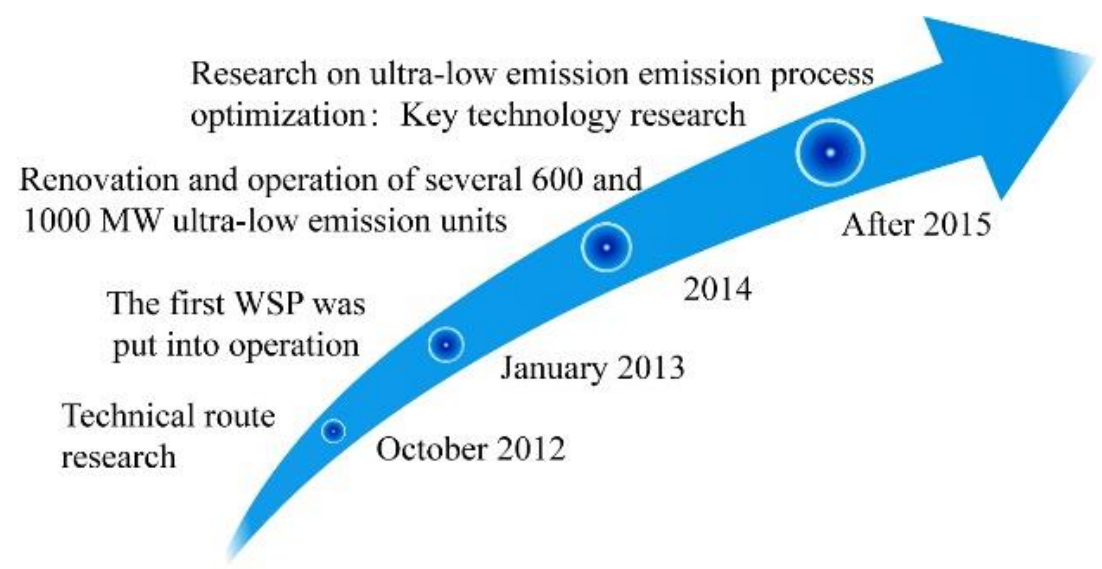

Fig. 1. Development and application of ultra-low emission technology for coal-fired flue gas.

particulate matter (CPM), heavy metals, etc. This improves the ambient air quality, especially reducing the occurrence of smog, which is the focus of public scrutiny (Li et al., 2019a; Yang et al., 2019).

In this paper, the emission reduction effects of primary pollutants, which could form fine particles such as $\mathrm{SO}_{3}, \mathrm{PM}_{2.5}$, and CPM, were introduced. The effects and environmental benefits of the ultra-low emission units were discussed based on the total particulate matter (TPM) emission.

\section{TPM FROM FLUE GAS}

\section{TPM}

U.S. EPA Method 202 (U.S. EPA, 2010) proposed a combined test method for FPM and CPM. In this method, TPM is the sum of FPM and CPM, and the test data include all particulate pollutants from coal-fired flue gas (Fig. 2) (Pei, 2010). FPM consists of pollutants in particulate and liquid states, and CPM consists of gaseous and vapor pollutants that easily condense into nuclei in atmospheric environments.

TPM is a crucial indicator of environmental quality. TPM contains previously unaccounted CPM in the current environmental monitoring system, and its pollutant component covers the majority of flue gas emissions. In addition to the investigation of the pollution reduction effects of $\mathrm{CPM}, \mathrm{SO}_{3}$, $\mathrm{PM}_{2.5}$ in various facilities, boiler flue gas treatment facilities are crucial to the analysis of emission reduction and factors influencing TPM.

\section{CPM}

In China, flue gas emissions of $\mathrm{PM}, \mathrm{SO}_{2}, \mathrm{NO}_{x}$, and $\mathrm{Hg}$ are monitored routinely. Some low-concentration pollutants, such as $\mathrm{SO}_{3}, \mathrm{PM}_{2.5}$, ammonia $\left(\mathrm{NH}_{3}\right)$, nitrates, volatile organic compounds, and heavy metals are generally neglected. However, these low-concentration pollutants also affect the environmental quality (Wang et al., 2016; Li et al., 2019b). Some pollutants are initially in the gaseous state in flue gas. Because of the decrease in the temperature and change in the pressure, the gaseous pollutants escaping from chimneys rapidly condense into small solid or liquid particles. These particles are known as condensable particulate matter (Li et al., 2019c). CPM contains sulfate ion $\left(\mathrm{SO}_{4}{ }^{2-}\right)$, nitrate ion $\left(\mathrm{NO}_{3}^{-}\right)$, nitrite ion $\left(\mathrm{NO}_{2}^{-}\right)$, chloride ion $\left(\mathrm{Cl}^{-}\right)$, ammonia ion $\left(\mathrm{NH}_{4}^{+}\right)$and $\mathrm{Ca}^{2+}, \mathrm{Mg}^{2+}, \mathrm{Fe}^{3+}, \mathrm{Na}^{+}, \mathrm{K}^{+}$, and heavy metal ions such as $\mathrm{Cu}, \mathrm{Mn}, \mathrm{Hg}$, As, $\mathrm{Cd}$. Among them, $\mathrm{SO}_{4}{ }^{2-}$ proportion (Wang et al., 2011) is the highest (61.50-68.86\%), and the metal element content is the lowest $(1 \%)$. The analysis showed that $\mathrm{SO}_{4}{ }^{2-}$ is derived from $\mathrm{SO}_{3} / \mathrm{H}_{2} \mathrm{SO}_{4}$ aerosol in flue gas. The current environmental monitoring system in China does not monitor these pollutants. According to the monitoring results of other country, CPM emitted by fixed sources is equal to or higher than that of PM currently monitored in China. Therefore, CPM should be monitored.

U.S. EPA Method 202 defines CPM as "a vapor at stack conditions, but that condenses and/or reacts upon cooling and dilution in the ambient air to form solid or liquid PM immediately after discharge from the stack, and is a component of primary PM." That is, except traditional emission standards set for PM equaled to FPM defined in EPA Method 202, CPM is also present in flue gas existed usually in the condensed form. The aerodynamic diameter of CPM is less than $1 \mu \mathrm{m}$, and CPM is harmful both to the human body and environment. Therefore, PM emitted by coal-fired flue gas is higher than the PM concentration currently monitored.

The monitoring results showed that CPM contributes considerably to $\mathrm{PM}_{10}$ in ambient air. Tests by Corio and Sherwell (2000) showed that the average concentration of CPM in flue gas from coal-fired boilers accounts for $76 \%$ of the total $\mathrm{PM}_{10}$ (by mass). The inductive analysis of 18 coalfired units in the United States showed that CPM accounted for an average of $49 \%$ (from $12 \%$ to $92 \%$ ) of TPM, and FPM accounted for $51 \%$ (from $8 \%$ to $88 \%$ ). It indicated that CPM emissions from coal-fired flue gas are equivalent to FPM emissions. Because of the generation mechanism, CPM consists of fine particles and has a larger share in $\mathrm{PM}_{10}$ and $\mathrm{PM}_{2.5}$. Pei (2000) showed that the average emission concentration of TPM from three coal-fired units in Shanghai (without the ultra-low emission retrofit) was approximately $41.8 \pm 12.3 \mathrm{mg} \mathrm{m}^{-3}$, and the average concentrations of FPM and CPM were $20.6 \pm 10.0$ and $21.2 \pm 3.5 \mathrm{mg} \mathrm{m}^{-3}$, respectively. CPM in TPM was approximately $50.7 \%$ (41.4-58.7\%). These test results were similar to those reported in the United 
Total particulate matter(TPM)

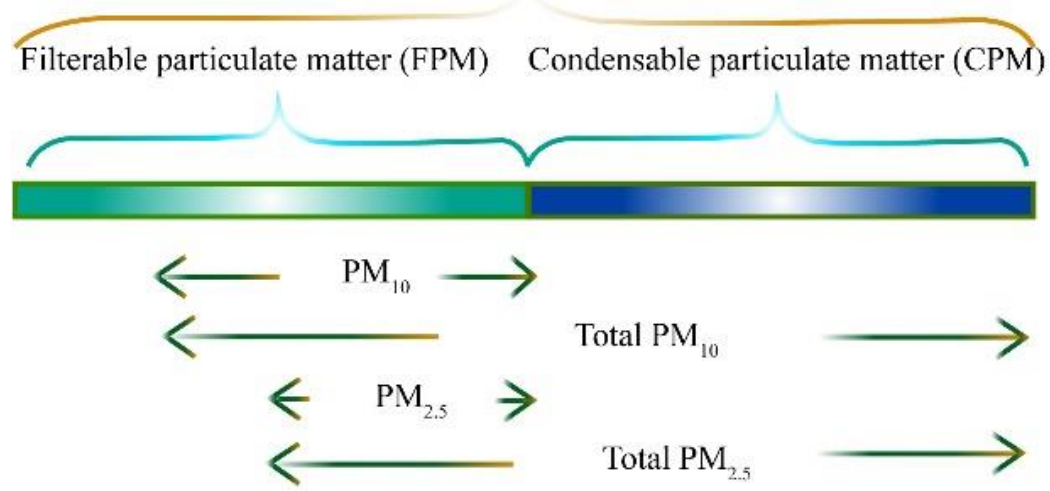

Fig. 2. Composition of total particulate matter.

States (Corio and Sherwell, 2000). After the ultra-low emission retrofit of the coal-fired units in Shanghai, our CPM emission monitoring test results showed that the average emission concentration was $5.07 \mathrm{mg} \mathrm{m}^{-3}$ when the average concentration of TPM was $7.36 \mathrm{mg} \mathrm{m}^{-3}$. CPM accounted for $53.7-83.3 \%$ of TPM, with an average of $68.9 \%$. These results showed that ultra-low emission retrofit can reduce FPM larger than CPM.

\section{TYPICAL ULTRA-LOW EMISSION UNIT AND CHARACTERISTICS OF PM REDUCTION}

\section{Ultra-low Emission Process}

The research of ultra-low emission technology for coalfired units in Shanghai was carried out earlier in China. The performance of ultra-low emission technology in Shanghai was evaluated on the $1000 \mathrm{MW}$ unit of Shanghai Shangdian Power Generation Co., Ltd., which was equipped with wet electrostatic precipitator first used in Chinese power stations. This precipitator was used for the study after approval from the National Development and Reform Commission. The resultant ultra-low emission process regional characteristics (shown in Fig. 3) and its technical features are as follows: 1) Cascade reduction design: PM is removed using the electrostatic precipitator and absorption tower, $\mathrm{NO}_{x}$ is removed through low-nitrogen combustion in a furnace and high-efficiency selective catalytic reduction (SCR) flue gas denitration, and $\mathrm{SO}_{2}$ is removed using a high-efficiency absorption tower. 2) Development and application of integrated absorption tower technology of high-efficiency desulfurization and dust removal: The absorption tower is equipped with a tray and wall ring, a three-stage high-efficiency defogging droplet reduction mechanism, and an optimized flow field. Because of the efficient PM-removal characteristics of the absorption towers, wet electrostatic precipitators are no longer used for end purification. 3) Full consideration of the synergistic reduction to multiple pollutants, mainly nonconventional pollutants such as $\mathrm{SO}_{3}, \mathrm{PM}_{2.5}, \mathrm{CPM}$, and $\mathrm{Hg}$ : Higher emission reduction can be obtained using lowtemperature electrostatic precipitators, high-efficiency integrated absorption towers, flue gas condensation, and low-temperature reheating, among other techniques. 4) Dry flue gas emissions do not harm the environment.

\section{Test Objects and Test Methods}

$\mathrm{PM}$ (including $\mathrm{PM}_{2.5}$ ), $\mathrm{CPM}$, and $\mathrm{SO}_{3}$ in flue gas were monitored in three typical ultra-low emission units in Shanghai (Table 1) to calculate TPM.

The dust concentration in the electrostatic precipitator inlet was tested using Pitot parallel sampling gravimetric method (GB16157). The sample was measured using Malvern laser particle-size analyzer to calculate the $\mathrm{PM}_{2.5}$ concentration. PM from the outlets of electrostatic precipitator and absorption tower was tested using ISO 12141:2002 (determination of mass concentration of particulate matter [dust] at low concentrations - manual gravimetric method), $\mathrm{PM}_{2.5}$ by using EPA Method 201A (determination of $\mathrm{PM}_{10}$ and $\mathrm{PM}_{2.5}$ emissions from stationary sources). EPA Method 202 (dry impinger method) was used for determining condensable particulate emissions from stationary sources. The $\mathrm{SO}_{3}$ test uses EPA Method 8 (determination of sulfuric acid and sulfur dioxide emissions from stationary sources).

\section{FPM}

PM emitted by coal-fired flue gas contains dust and desulfurized gypsum, in which particle size is usually less than $10 \mu \mathrm{m}$. When the dust is carried with flue gas through a low-temperature electrostatic precipitator, approximately $99.9 \%$ of the dust accumulates. After passing flue gas through the high-efficiency desulfurization and dust-removal integrated absorption tower, a dust-removal efficiency of more than $75 \%$ can be achieved, and a PM emission concentration lower than $5 \mathrm{mg} \mathrm{m}^{-3}$, which contains desulfurized gypsum, is formed because of the escape of droplets.

Before passing through the electrostatic precipitator, the $\mathrm{PM}_{2.5}$ concentration in dust is relatively low. After cascade dust removal, the removal rate of the large particles is higher than that of the fine particles, and the final $\mathrm{PM}_{2.5}$ concentration in PM increases considerably (Jaworek et al., 2018). The test results of $\mathrm{PM}$ and $\mathrm{PM}_{2.5}$ for electrostatic precipitators and desulfurization absorption towers in the three ultra-low emission units are listed in Table 2. Fig. 4 illustrates the results of the PM particle-size distribution at the entrance of the electrostatic precipitator.

The test results showed that the $\mathrm{PM}_{2.5}$ concentration in PM at the inlet of the electrostatic precipitator varied between 


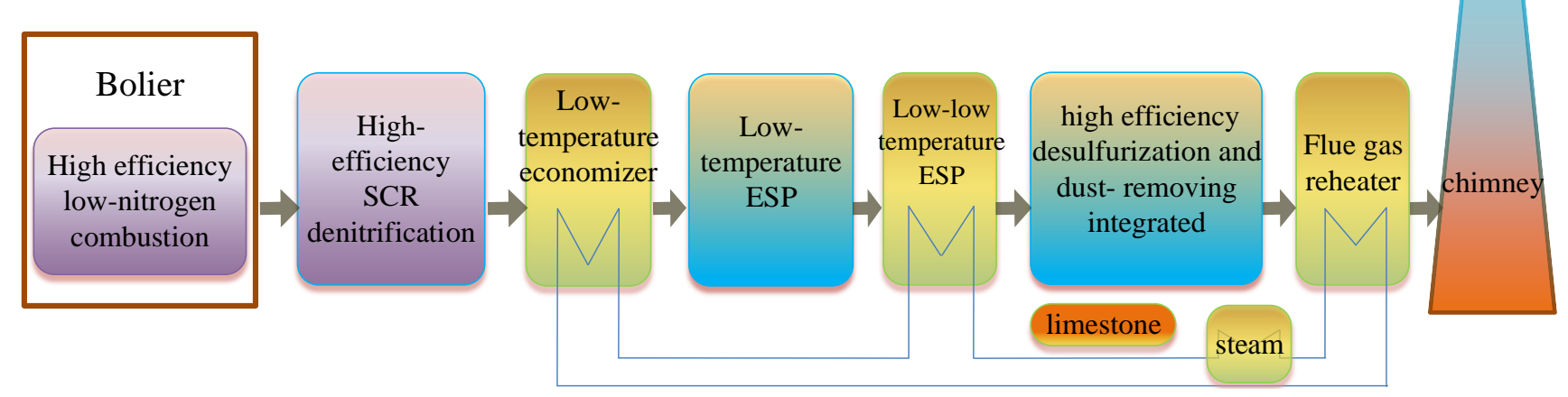

Fig. 3. Schematic of typical process for ultra-low-emission of coal-fired units.

Table 1. Ultra-low-emission process of coal-fired units A, B, and C.

\begin{tabular}{lll}
\hline Unit & Unit capacity & Ultra-low emission process \\
\hline A & $1000 \mathrm{MW}$ & $\begin{array}{l}\text { low-nitrogen combustion } \rightarrow \text { SCR denitration } \rightarrow \text { low-temperature electrostatic precipitator } \rightarrow \\
\text { desulfurization and dedust integrated tower } \rightarrow \text { horizontal wet electric dust removal } \rightarrow \text { flue gas } \\
\text { reheater }\end{array}$ \\
B $\quad 1000 \mathrm{MW}$ & $\begin{array}{l}\text { Low-nitrogen combustion } \rightarrow \text { SCR denitration } \rightarrow \text { electric dust removal } \rightarrow \text { high-efficiency } \\
\text { desulfurization } \rightarrow \text { flue gas condensation and water removal } \rightarrow \text { flue gas reheater (low- } \\
\text { temperature) } \\
\text { Low nitrogen combustion } \rightarrow \text { SCR denitration } \rightarrow \text { low-low temperature electrostatic precipitator } \\
\rightarrow \text { desulfurization and dedust integrated tower } \rightarrow \text { horizontal mist remover } \rightarrow \text { flue gas reheater }\end{array}$ \\
& $660 \mathrm{MW} \quad$ &
\end{tabular}

Table 2. Removal rate of PM and $\mathrm{PM}_{2.5}$ for ESP and FGD.

\begin{tabular}{rllllll}
\hline Unit & $\begin{array}{l}\text { Inlet } \mathrm{PM}_{2.5} \\
\text { concentration } \\
\left(\mathrm{mg} \mathrm{m}^{-3}\right)\end{array}$ & $\begin{array}{l}\text { Outlet } \mathrm{PM}_{2.5} \\
\text { concentration } \\
\left(\mathrm{mg} \mathrm{m}^{-3}\right)\end{array}$ & $\begin{array}{l}\mathrm{PM}_{2.5} \text { removal } \\
\text { efficiency } \\
(\%)\end{array}$ & $\begin{array}{l}\text { Inlet FPM } \\
\text { concentration } \\
\left(\mathrm{mg} \mathrm{m}^{-3}\right)\end{array}$ & $\begin{array}{l}\text { Outlet FPM } \\
\text { concentration } \\
\left.\mathrm{m}^{-3}\right)\end{array}$ & $\begin{array}{c}\text { FPM removal } \\
(\%)\end{array}$ \\
\hline ESP & & & & & & \\
A & 811.90 & 3.810 & 99.53 & 6526.90 & 11.10 & 99.83 \\
B & 1167.50 & 6.06 & 99.48 & 6482.80 & 14.90 & 99.77 \\
C & 418.40 & 4.17 & 99.00 & 7663.30 & 12.26 & 99.84 \\
FGD & & & & & & \\
A & 3.81 & 0.99 & 74.02 & 11.10 & 1.72 & 84.50 \\
B & 6.06 & 1.79 & 70.46 & 14.90 & 3.10 & 79.19 \\
C & 4.17 & 1.30 & 68.82 & 12.26 & 2.56 & 79.12 \\
\hline
\end{tabular}

$5.5 \%$ and $18.0 \%$, and the range fluctuated considerably. The $\mathrm{PM}_{2.5}$ content was affected by factors such as the coal quality, coal preparation, combustion condition, SCR catalyst and its flow field, $\mathrm{SO}_{3}$ content, and escaped ammonia concentration. For fine pulverized coal, the SCR denitrification system was installed, and the concentrations of $\mathrm{SO}_{3}$ and escaped ammonia were high, and the $\mathrm{PM}_{2.5}$ content increased.

Using an electrostatic precipitator, dust and $\mathrm{PM}_{2.5}$ removal efficiencies in the range of $99.77-99.83 \%$ and 99.00 $99.53 \%$ were achieved for the three units. The removal rates are higher than that of the conventional electrostatic precipitator because the removal mechanism of the particles with different particle size is different in the electric field. Larger particles $(\geq 2.0 \mu \mathrm{m})$ were removed because of the electric field charge, whereas fine particles $(\leq 0.1 \mu \mathrm{m})$ were mainly removed because of the diffusion charge, and the particles between 0.1 and $2.0 \mu \mathrm{m}$ were controlled using an electric field charge and diffusion charge mixing control zone. Therefore, the charging effect was inadequate, and the removal efficiency was relatively low in the conventional electrostatic precipitator.

After passing through the desulfurization absorption tower, subsequent flue gas treatment facilities and flue gas reheating (Table 1), 79.12-84.50\% and 68.82-74.02\% removal rates were obtained for $\mathrm{PM}$ and $\mathrm{PM}_{2.5}$. Tray synergism, highefficiency defogging, and flow field optimization measures are implemented in the high-efficiency desulfurization and dust-removing integrated absorption tower. PM is subjected to high-efficiency washing of the liquid-holding layer of the tray in the tower and sprays with high liquid/gas ratios. The dust-removal efficiency of this method is considerably higher than that of the traditional absorption tower. The $\mathrm{PM}_{2.5}$ removal effect was especially enhanced. In addition, under high-efficiency defogging and optimized flow fields, 


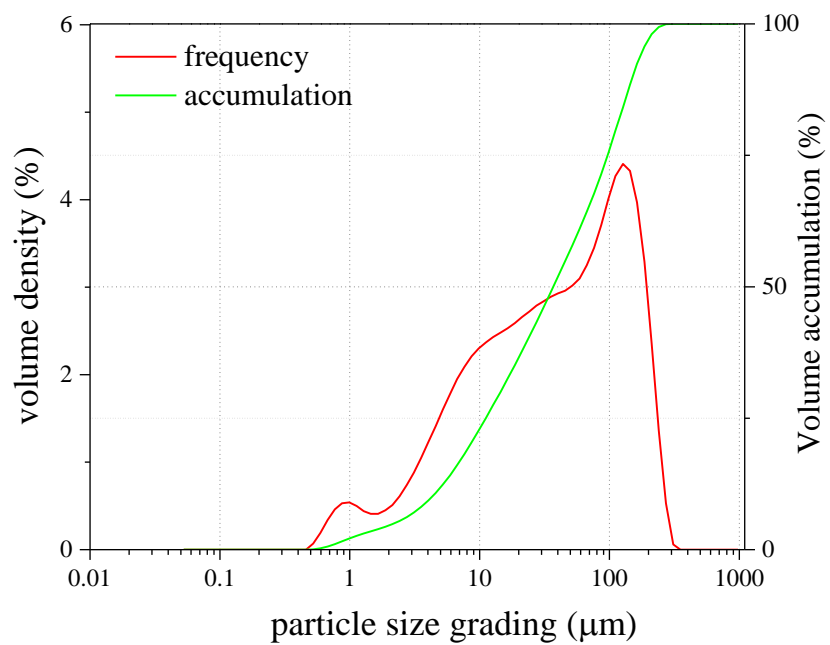

a. $\mathrm{PM}_{2.5}$ accounted for $12.4 \%$ in unit $\mathrm{A}$

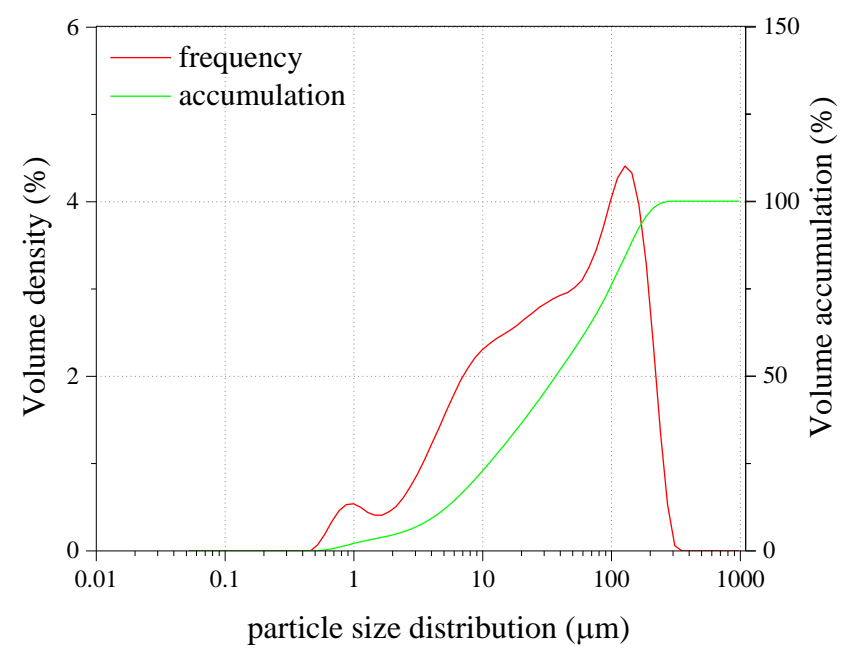

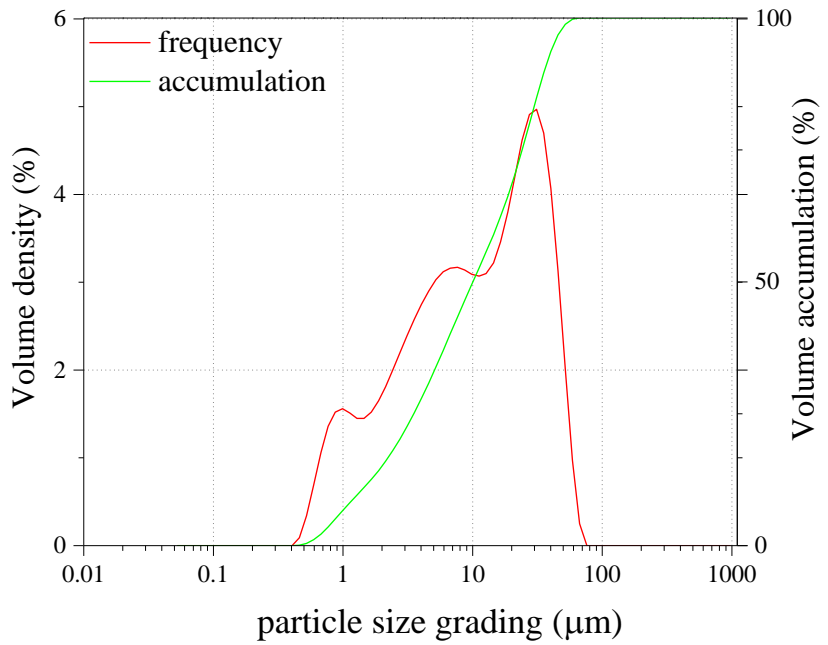

b. $\mathrm{PM}_{2.5}$ accounted for $18.0 \%$ in unit $\mathrm{B}$

c. $\mathrm{PM}_{2.5}$ accounted for $5.5 \%$ in unit $\mathrm{C}$

Fig. 4. PM particle-size distribution at the inlet of ESP A, B, and C.

the concentration of the escaped droplet reduced from approximately 75 to $\leq 20 \mathrm{mg} \mathrm{m}^{-3}$, which markedly reduced the escape rate of desulfurization gypsum, and an ultra-low $\mathrm{PM}$ emission value of $5 \mathrm{mg} \mathrm{m}^{-3}$ was obtained.

From the experimental results, the removal rate of $\mathrm{PM}_{2.5}$ using the traditional absorption tower is speculated to be higher than that obtained using the modified method. The removal rate of $\mathrm{PM}_{2.5}$ is affected by the escape of the droplets, which reduces the $\mathrm{PM}_{2.5}$ removal rate. Experimental results showed that $\mathrm{PM}_{2.5}$ concentration exhibits a trend of increase. This is caused by the high escape rate of the fog droplets.

The analysis of the removal effect of PM with the ultralow emission system revealed that the PM concentrations from the chimney in Units A, B, and C were 1.72, 3.10, and $2.56 \mathrm{mg} \mathrm{m}^{-3}$ and total dust-removal rates were $99.97 \%$, $99.95 \%$, and $99.97 \%$, respectively. The proportion of $\mathrm{PM}_{2.5}$ in PM was 50.7-57.7\%. The corresponding removal rates of $\mathrm{PM}_{2.5}$ were $99.878 \%, 99.847 \%$, and $99.689 \%$, respectively. Thus, the removal rate of the ultra-low emission system was considerably higher than the conventional-unit $\mathrm{PM}_{2.5}$ removal rate (95.68-98.47\%) (Tao et al., 2018). The emission reduction effect of PM was obviously, and the higher emissionreduction efficiency was achieved.

\section{Sulfur Trioxide}

Sulfur trioxide is the main component of CPM (approximately $60 \%$ or more). The efficient removal of $\mathrm{SO}_{3}$ with ultra-low emission systems reduces both CPM and TPM.

$\mathrm{SO}_{3}$ in flue gas is affected by temperature, oxygen content, humidity, and catalytic substances (Zheng et al., 2019). After passing through the flue gas system, $\mathrm{SO}_{3}$ concentration and morphology change. $\mathrm{SO}_{3}$ test data for the process of the ultra-low emission system in Unit A showed that the comprehensive removal rate was as high as $96.0 \%$ because of process cascade reduction (Tao et al., 2018).

The sulfur contents of coal for Units A, B, and C were $0.21 \%, 0.36 \%$, and $0.39 \%$, respectively. The test results of $\mathrm{SO}_{3}$ under full-load operation conditions in the process are depicted in Table 3. Experimental results showed that the concentration of $\mathrm{SO}_{3}$ decreased gradually from the inlet of the electrostatic precipitator to the outlet of the chimney. 
Table 3. Change of flue gas $\mathrm{SO}_{3}$ concentration with unit process $\left(\mathrm{mg} \mathrm{m}^{-3}\right)$.

\begin{tabular}{llllll}
\hline Unit & ESP inlet & ESP outlet & FGD outlet & WESP outlet & Chimney outlet \\
\hline A & 26.98 & 12.39 & 4.22 & 1.99 & 1.91 \\
B & 19.21 & 14.52 & 4.57 & $2.83^{*}$ & 2.50 \\
C & 25.60 & 8.60 & - & $2.54^{* *}$ & 1.95 \\
\hline
\end{tabular}

${ }^{*}$ refers to the outlet of the condensing dehydrator; ${ }^{* *}$ refers to the outlet of the flue demister.

The $\mathrm{SO}_{3}$ removal efficiencies of the electrostatic precipitators for $\mathrm{A}, \mathrm{B}$, and $\mathrm{C}$ were $54.08 \%, 24.41 \%$, and $66.41 \%$, respectively. The test results were considerably affected by the operating temperature of the electrostatic precipitator (Table 1). This indicated a tendency of increase in the removal rate with the decrease in the smoke temperature.

The measured data from FGD showed that the $\mathrm{SO}_{3}$ removal rates of the three units were $65.94 \%, 68.53 \%$, and $70.46 \%$, respectively. Among them, Unit C had one more secondary flue defogger. Thus, the ability of high-efficiency desulfurization absorption tower to reduce $\mathrm{SO}_{3}$ synergistically is strengthened and the removal rate is relatively stable.

The unit emission data showed that the $\mathrm{SO}_{3}$ concentration levels of the three units were similar, and the average emission concentration was $2.12 \mathrm{mg} \mathrm{m}^{-3}$. The comprehensive removal rates were $92.92 \%, 86.99 \%$, and $92.38 \%$ respectively, with an average of $90.76 \%$. Similar to those of the ultra-lowreform unit shown by Tao et al. (2018), the emission concentration was $0.80-3.68 \mathrm{mg} \mathrm{m}^{-3}$, and the average removal rate was $90.7 \%$.

\section{CPM}

CPM contains pollutants such as sulfur trioxide, ammonium salts, nitrates, volatile organic compounds, and heavy metals. Efficient step-by-step removal by the ultralow emission systems considerably reduced most of these pollutants. The PM emissions of some units higher than 660 MW in Shanghai are listed in Table 4.

The data in Table 4 shows that the emission FPM was approximately $1.17-3.93 \mathrm{mg} \mathrm{m}^{-3}$, and the average concentration was $2.29 \pm 1.20 \mathrm{mg} \mathrm{m}^{-3}$. The CPM concentration was $1.65-8.56 \mathrm{mg} \mathrm{m}^{-3}$, and the average concentration was $5.07 \pm 2.62 \mathrm{mg} \mathrm{m}^{-3}$. TPM is the sum of FPM and CPM, and its concentration was between 3.07 and $12.53 \mathrm{mg} \mathrm{m}^{-3}$, and the average concentration was $7.36 \pm 3.56 \mathrm{mg} \mathrm{m}^{-3}$. The ratio of CPM to TPM was 53.7-83.3\%, with an average ratio of $67.6 \pm 9.43 \%$.

The CPM emission concentration of ultra-low emission units was twice that of FPM. For the thermal coal quality at Shanghai, the TPM emission concentration of ultra-low emission units was approximately three times that of FPM. After ultra-low reform, the CPM emission concentration decreased by $76 \%$, and the ratio of FPM to CPM decreased from 1:1 to 1:2. But even so, because of the efficient removal of ultra-low emissions, the actual emission of TPM was lower than the traditional Shanghai power unit (Pei, 2010), and the emission reduction rate was approximately $82 \%$.

\section{TPM and Emission Concentration}

Table 4 provides the TPM emissions data of some coalfired units in Shanghai. The following aspects are crucial: 1) The data provided are based on the emission monitoring data of $660 \mathrm{MW}$ and $1000 \mathrm{MW}$ coal-fired units for Shanghai's thermal coal quality. The concentration range and average value of these data are representative to some extent. The average value of $7.36 \mathrm{mg} \mathrm{m}^{-3}$ can provide basic data for environmental assessment. 2) The test results showed that the TPM concentration of the ultra-low emission unit was approximately three times that of the FPM concentration. The emissions data appeared to be underestimated. Compared with the traditional flue gas treatment process that does not have the ultra-low emission retrofit, TPM was considerably reduced. Compared with the FPM emission concentration before the reform, the emission reduction rate was higher than $60 \%$. Substantial emission reduction was achieved from coal-fired units. 3) The key to TPM reduction in the ultra-low-scale flue gas process is efficient synergistic removal of PM and unconventional contaminants. Optimizing the ultra-low flue gas process is a crucial task in the postultra-low era.

Table 4. Test results of FPM, CPM, and TPM from some ultra-low emission units.

\begin{tabular}{lllll}
\hline Unit & $\begin{array}{l}\text { FPM concentration } \\
\left(\mathrm{mg} \mathrm{m}^{-3}\right)\end{array}$ & $\begin{array}{l}\text { CPM concentration } \\
\left(\mathrm{mg} \mathrm{m}^{-3}\right)\end{array}$ & $\begin{array}{l}\text { TPM concentration } \\
\left(\mathrm{mg} \mathrm{m}^{-3}\right)\end{array}$ & $\begin{array}{l}\text { CPM/TPM } \\
(\%)\end{array}$ \\
\hline A & 1.38 & 6.87 & 8.25 & 83.3 \\
B & 1.63 & 2.30 & 3.93 & 58.5 \\
C & 1.42 & 1.65 & 3.07 & 53.7 \\
D & 1.17 & 3.93 & 5.10 & 77.1 \\
E & 1.61 & 3.41 & 5.02 & 67.9 \\
F & 3.93 & 7.18 & 11.11 & 64.6 \\
G & 3.21 & 6.68 & 9.89 & 67.5 \\
H & 3.97 & 8.56 & 12.53 & 68.3 \\
average & $2.29 \pm 1.20$ & $5.07 \pm 2.56$ & $7.36 \pm 3.56$ & $67.6 \pm 9.43$ \\
Average value of three & $20.6 \pm 10.0$ & $21.2 \pm 3.5$ & 41.8 & 49 \\
conventional units (Pei., 2010) & & & & \\
\hline
\end{tabular}




\section{CONCLUSION}

1) PM in coal-fired flue gas contains FPM and CPM, the sum of which equals TPM. Whereas FPM comprises filterable solid and liquid contaminants, CPM consists mainly of $\mathrm{SO}_{4}{ }^{2-}$, plus various anions, cations, and metallic ions, and precipitates in the form of condensed nuclei after the discharge of the flue gas. TPM is a vital indicator of flue gas emissions from coal-fired units, which must be considered when evaluating the air quality of the atmospheric environment, including the severity of haze.

2) The $\mathrm{PM}_{2.5}$ in FPM strongly affects the air quality. The $\mathrm{PM}_{2.5}$ removal rates of the tested power plants considerably improved after they were equipped with ultra-low emission technology, resulting in emitted concentrations of $0.99-1.79 \mathrm{mg} \mathrm{m}^{-3}$, or comprehensive removal rates of 99.689-99.878\%. The $\mathrm{SO}_{3}$ in the flue gas, which is the primary source of CPM, decreased to $1.91-2.50 \mathrm{mg} \mathrm{m}^{-3}$ in concentration, exhibiting comprehensive removal rates of $86.99-92.92 \%$ (averaging $90.76 \%$ for the three tested units). Thus, both the $\mathrm{PM}_{2.5}$ and the $\mathrm{SO}_{3}$ were significantly reduced.

3) The ultra-low emission retrofit of the tested units noticeably reduced the generated FPM and thus CPM, producing a smaller FPM/CPM ratio (1:2 vs. 1:1). The emitted concentrations of CPM and TPM dropped by $76 \%$ and $82 \%$, respectively. The decrease in $\mathrm{PM}_{2.5}$ and $\mathrm{SO}_{3}$ also caused a decrease in CPM.

4) The TPM emission values obtained in this study, which investigated typical ultra-low emission units in Shanghai, are representative. Therefore, they provide basic data for environmental assessment and local environmental policy formulation.

\section{ACKNOWLEDGEMENTS}

This study was supported by the Shanghai Science and Technology Committee (No. 18DZ1202500). This manuscript was edited by Wallace Academic Editing.

\section{REFERENCES}

Chen, X.M., Liang, Q.M., Liu, L.C., Wang, C. and Xue, M.M. (2019). Critical structural adjustment for controlling China's coal demand. J. Cleaner Prod. 235: 317-327. https://doi.org/10.1016/j.jclepro.2019.06.315

Corio, L.A. and Sherwell, J. (2000). In-stack condensible particulate matter measurements and issues. J. Air Waste Manage. Assoc. 50: 207-218. https://doi.org/10.1080/10 473289.2000.10464002

Han, S., Chen, H., Long, R. and Cui, X. (2018). Peak coal in China: A literature review. Resour. Conserv. Recycl. 129: 293-306. https://doi.org/10.1016/j.resconrec.2016.08.012

Jaworek, A., Marchewicz, A., Sobczyk, A.T., Krupa, A. and Czech, T. (2018). Two-stage electrostatic precipitators for the reduction of $\mathrm{PM}_{2.5}$ particle emission. Prog. Energy Combust. Sci. 67: 206-233. https://doi.org/10.1016/j.pec s.2018.03.003
Li, J., Ma, X., Zhang, Z. and Yang, L. (2019a). Emission of coal-fired VOCs and prospect of control technology. Chem. Ind. Eng. Prog. 38: 5539-5547. (in Chinese) https://doi.org/10.16085/j.issn.1000-6613.2019-0380

Li, J., Wang, C., Pan, Z., Jiang, Z., Chen, L., Zhang, Y., Pan, J., Wang, C., Li, J. and Liu, R. (2019b). Analysis of ${ }^{210} \mathrm{~Pb}$ and ${ }^{210} \mathrm{Po}$ emissions from coal-fired power plants. Fuel 236: 278-283. https://doi.org/10.1016/j.fuel.2018.08.075

Li, X., Zhu, F., Duan, J., Li, J., Yang, L. and Zhang, W. (2019c). An overview of condensable particulate matter emission from stationary sources. Chem. Ind. Eng. Prog. 38: 5091-5102. (in Chinese) https://doi.org/10.16085/j.i ssn.1000-6613.2019-0268

Pei, B. (2010). Discussion on the Emission Issues and testing of condensable particulate matter from exhaust gas of stationary source. Environ. Monit. China 26: 9-12. (in Chinese) http://www.cnemce.cn/ch/reader/view_abstract.a spx?file_no $=20100604$

Tao, L., Weng, J., Li, X., Yue, C., Wang, J., Ai, C. and Dong, F. (2018). Analysis on coordinated reduction of $\mathrm{SO}_{3}$ in whole process of ultra-low emission in coal-fired flue gas. Electr. Power 51: 177-184. (in Chinese)

U.S. EPA (2010). Method 202 Dry impinger method for determining condensable particulate emissions from stationary source. United States Environmental Protection Agency. https://www.epa.gov/sites/production/files/201708/documents/method_202.pdf

Wang, S., Zhu, F., Wang, H., Zuo, Y., Sun, X., Zhao, X., Chen, H. and Liu, G. (2011). Fine particle emission characteristics from coal-fired power plants based on field tests. Acta Sci. Circumst. 31: 630-635. (in Chinese)

Wang, Y., Cheng, K., Tian, H.Z., Yi, P. and Xue, Z.G. (2016). Emission characteristics and control prospects of primary $\mathrm{PM}_{2.5}$ from fossil fuel power plants in China. Aerosol Air Qual. Res. 16: 3290-3301. https://doi.org/10. 4209/aaqr.2016.07.0324

Yang, Y., Li, H., Zhao, H., Qu, R., Zhang, S., Hu, W., Yu, X., Zhu, X., Liu, S., Zheng, C. and Gao, X. (2019). Structure and crystal phase transition effect of Sn doping on anatase $\mathrm{TiO}_{2}$ for dichloromethane decomposition. $J$. Hazard. Mater. 371: 156-164. https://doi.org/10.1016/j.j hazmat.2019.02.103

Zhao, Y.C., Ma, S.M., Yang, J.P., Zhang, J.Y. and Zheng, C.G. (2015). Status of ultra-low emission technology in coal-fired power plant. J. China Coal Soc. 40: 2629-2640. (in Chinese with English Abstract) http://www.mtxb.com.c n/EN/Y2015/V40/I11/2629

Zheng, H., Wang, Y., Liu, Y., Yang, Z., Qu, R., Ye, D., Liang, C., Liu, S. and Gao, X. (2019). Formation, transformation, measurement, and control of $\mathrm{SO}_{3}$ in coalfired power plants. Fuel 241: 327-346. https://doi.org/10. 1016/j.fuel.2018.12.039

Received for review, February 28, 2020

Revised, May 13, 2020

Accepted, May 13, 2020 